\title{
Effects of Leadership Styles on Ethiopian Banking Industry Performance
}

\author{
Tariku lagesse* \\ College of Business and Economics, Jimma University \\ Kenenisa Lemi \\ College of Business and Economics, Jimma University \\ Debebe Alemu \\ College of Business and Economics, Jimma University
}

\begin{abstract}
The aim of the study was to examine the effect of leadership styles on organizational performance with specific reference to Commercial banks operate in Jimma Town. To achieve the objectives the study causal type of research and panel design was used to examine the amount of effect that leadership style could exert on the bank's performance. The primary data sources were leaders on different levels and their subordinate employees while, the secondary data sources were annual report of individual banks and from audit financial report of National Bank of Ethiopia. Multifactor Leadership Questionnaire was adapted for collection of leadership styles representing questions. The descriptive and inferential analyses was conducted to analyze the collected data. Subsequently, the researcher employed Random Effect Model to investigate the extent of relationship between independent variables and dependent variables. The study results revealed that both transformational and transactional leadership have strong positive effect on the ROA. Thus, transformational that brings changes in working environment by inspiring and motivating employees for changes, creation, innovation, to go beyond from what they actually think they can; and transactional that reward employees and make recognition in exchange for the work they perform, giving close directions and guidance have positive and significant effect in promoting the performance of the bank. Based on the study results the provided recommendation was that the leaders of banks should focus on playing a role model by taking first step of what they talk about and keep consistent in their action in way that getting trust and loyalty from employees and in instilling confidence, commitment and vision in employees and the Stakeholders in the industry should consider taking banking in a non-traditional direction by placing more emphasis on understanding leadership style and its effects on improving results.
\end{abstract}

Keywords: Effect; Leadership Style; Performance; Banks; Jimma; Ethiopia

DOI: $10.7176 / \mathrm{EJBM} / 12-16-02$

Publication date:June 30th 2020

\section{Introduction}

Leadership, as defined by Northouse (2004), is a process whereby an individual influence a group of individuals to achieve a common goal. Leadership style is the way in which that process is carried out. Performance is the accomplishment and execution of tasks. According to Albrecht (2011), performance is the extent to which an organization achieves a set of pre-defined targets that are unique to its mission. Leadership style is a key determinant of the success or failure of any organization. Thus, ensuring the effective leadership is becoming a critical issue for the success of modern business organization and the focus on it is increasing recently as the challenge of running business is enormous. So far, several theories had emerged and paved the way for the coming of modern leadership styles that can be understood in the organizational context.

Transformational and transactional are the two recent leadership styles that researchers have been suggesting for organizational success in different circumstance. Compared to others, the financial sector in Sub Saharan Africa is lagging behind (Kefela 2008). Ethiopia is no exception to it. The less infrastructure facilities (technology, service delivery, less capital) and ineffective management system have been the main reason among others that makes Ethiopian banking industry to remain closed for foreign investors and continue to operate in unique business environment even from its neighboring East African countries like Kenya, Tanzania, and Uganda. The least development of social and economy signifies the malfunctioning of banking sector in the country. However, Kefele (2008), points out that the loose in management system within individual banks is the cause for all problems in the banking sector (Kefela,2008).

The banking industry is the most important financial institution in Ethiopia, dominating most of financial activities. Moreover, the sector is not well developed and less integrated with global financial market and the market is not competitive (ILO, 2009). Less infrastructure development: technology, service delivery, less capital, and ineffective management system are discernible features in Ethiopian banking sector. Effective leadership in an organization is very important for continued prosperity, commercial banks notwithstanding. The banking 
industry in Ethiopia has witnessed tremendous changes brought about by globalization, intense competition among rivals, changing regulatory guidelines, technology, and more demanding customers. These changes and dynamic business environment require leadership that can enable both the people and the organization to adapt and be successful.

Banks in Ethiopia sticks to traditional ways of doing things. Engaging on daily routine work is the common duties of both managers and employees. Most of managers are spending their time on routine duties like attendance and dress code monitoring, writing related rules and regulations that urges the following of punishment for any deviation happened against the outlined rule. This high focuses on irregularities, mistakes, exceptions, and deviations are consuming much time of mangers and making them to be less effective on prediction about the future and relating the work at hand with the articulated vision of the bank. Moreover, wide gap is observed in understanding of the vision and the mission of the bank among the workers. There are only few managers that clearly communicate what the vision is and confident in attainment of it.

On the other hand, employees are complaining as their individualistic and communal need is not well considered and less room is given for their say. This discourages employees to feel belongingness to the bank which in turn leads to less productivity. Their voice is continued to be ignored and no room is being given for their say. They are not participating in the decision process that all policies and big decisions reveled to them after it is made at the top. There is visible bridge between managers and employees that no free discussion is possible and most employees are not comfortable to share what they think. These show the seriousness of leadership malfunctioning in Ethiopian banking industry. Ensuring the presence of effective leadership is one the critical strategies suggested by Bass \&Avoilo (1999) to increase the performance and remain in business.

The leadership style drives the ability of an organization, to successfully implement business strategies, to gain a competitive advantage and optimize human capital (Teshome, 2011). The dependency of organizational performance on the leadership effectiveness has been demonstrated by several studies (Chung-Wen Young 2008; Teshome, 2011; Cole 2009; Wang et al 2011; Muejohn et al 2012,). Even though some studies support the superiority of transformational leadership style over transactional leadership style, the other claim the superiority of transactional leadership style over transformational leadership style for better organizational performance; some still suggests the combination of both leadership styles with various degrees according to the situation. In line with this, the study will be examining the effect of leadership styles (i.e. transformational and transactional leadership) on organizational performance in case of Commercial banks operate in Jimma Town.

The specific objectives of the study are:

- To investigate the of effect of transformational leadership style on Banks performance

- To investigate the of effect of transitional leadership style on Banks performance

- To examine the relation of transformational and transitional leadership style has with Banks performance.

\section{Research Hypothesis}

Keeping in view the nature and objectives of the study the following hypothesis have been formulated and tested.

H1: Transformational leadership affects organizational performance directly and significantly.

H2: Transactional leadership affects organizational performance directly and significantly.

\section{Significance of the Study}

This study adds more knowledge to an existing body of literature on the concept of leadership and performance from Ethiopian context. The study is shed more light on the relationship between leadership styles adopted by the leaders of banking institutions and the performance of the institutions. Hence, the outcome of the study can also be used as a basis of further research and also in academics in the area of leadership and performance. The findings from this study may further be used by policy makers in the banking industry to design policies that promote responsible leadership for performance. Senior bank executives can use outcomes from the study to make critical examination of existing leadership styles in their organizations which may assist them work towards improvement of the present leadership strategies.

\section{Theoretical Frameworks}

The four major components of transformational leadership style are Idealized influence, Inspirational Motivation, Intellectual Stimulation and Individual Consideration (Ristow 1997, Shibru \&Darshan, 2011, Amir Sadeghi 2012).

\section{Idealized Influence}

Idealized influence is one of the components of transformational leadership style that the leader's employee to get superior results. It is a component where being a role model of a leader can be perceived by followers so as it inspires them (Moss \&Ritossa, 2007). The followers can identify their role model easily and try to imitate as they admire, respect, and trust them (Bass et al, 2003). This is achieved by the fact that they share risks with their followers and, importantly, they are consistent, rather than arbitrary. Leaders with idealized characteristics are the 
role models that they walk first on the way they talk about (Avolio: 2005). Again, the transformational leader with an idealized influence are highly disciplined who do not use power for their own personal gain; they display high standards of moral and ethical conduct (Ristow, 1997). The idealized influence also relates to charisma which, for long has been held as a mystical gift that people possess. It is true that there is more to being a leader than being a charismatic person.

\section{Inspirational Motivation}

Inspirational Motivation is a component of transformational leadership style that describes the degree that the leader states attractive and encouraging vision to followers. Transformational leaders motivate and inspire those around them by providing meaning and challenge to their followers' work. They also focus strongly on team spirit. Followers are included in developing inspiring future visions and the leaders are effective communicators. The transformational leaders communicate their expectations clearly with their followers. They also display commitment to goals and the shared vision. These leaders talk optimistically about the future and what needs to be done to achieve the vision (Ristow, 1997).

\section{Intellectual Stimulation}

Intellectual stimulation is a component of the transformational leadership that refers to the degree in which the leaders stimulate their followers to be innovative and creative. Transformational leaders stimulate their followers to be innovative and creative by questioning assumptions, reframing problems, and approaching old situations in new ways. They encourage creativity through the use of reasoning and evidence rather than unsupported opinion to solve such problems (Avolioet al, 1991:6). The transformational leader encourages the development of a culture of continuous questioning and thus continuous learning (Ristow, 1997).

\section{Individualized Consideration}

Individualized Consideration is a component of the transformational leadership style that explains the degree in which the leader pays attention to the need of individual employee. Transformational leaders pay attention to the individual employee and his or her needs rather than treating all followers alike and having the same needs. Time is spent teaching and coaching others in an effort to develop their strengths and promote self-development, by acting as coaches and mentors. The transformational leaders make sure that the employee has sufficient help and the resources necessary to complete the tasks at hand (Ristow, 1997)

Bass (1985) distinguishes two leadership factors within transactional leadership, namely contingent reward and management-by-exception.

Contingent Reward refers to situations in which the leader gives compensation to employees when they perform according to contract or expectation. The leader will assign or get agreement on what needs to be done. The leader then promises rewards, or actually rewards others, in exchange for satisfactorily carrying out the assignment. Bass and Avolio (1994) contend that contingent reward has been found to be reasonably effective as a style of leadership. It is, however, not as effective as the transformational leadership factors, which will be discussed in the next section, in motivating others to achieve higher levels of development and performance.

Management-by-Exception explains the degree in which a leader watches follower closely for mistakes or role violations (Northouse, 2007). Passive management-by-exceptions used by leaders who only interfere in the employees work if they do not meet the desired goals. The leader waits passively for deviances, mistakes, and errors to happen and then take corrective action (Judge \& Piccolo, 2004; Bass \&Avolio, 1994). This type of leader avoids describing agreements, explaining expectations and standards to be achieved by subordinates, but will intervene after particular problems become apparent (Amir Sadeghi,et at 2012).

Active management-by-exception refers intervening in people's work when they are not putting forth the effort expected of them(Pruijn and Boucher, 1994:75). Leaders will arrange actively to monitor deviances from standards, mistakes and errors in the follower's assignments and will take corrective action as necessary. Bass and Avolio (1994) demonstrate that although management-by-exception is necessary in some situations, it is generally ineffective as it is a prescription for mediocrity. Managers who rely heavily on passive management-by-exception, usually only attempt to sort problems out when they become chronic, which in many instances is too late. Those who employ active management-by-exception on a regular basis tend to focus too heavily on mistakes and in this way demotivate the workforce.

\section{Organizational Performance}

Performance is a multidimensional construct and therefore multiple measures of performance should be used (Lumpkin and Dess, 1996). Growth has been argued as an essential element to the attainment of sustainable competitive advantages and profitability (Markman and Gartner, 2002) and it is hard to associate sustained growth without profitability (Fitzsimmonset al., 2005). Evaluation of bank performance traditionally includes the four performance measures: ROA, efficiency ratio, net interest margin, and return on equity (McCune, 2007) [cited in 
by Cole, 2009]. Return on total assets (ROA) is known to measure the effectiveness of managerial performance and one of the most frequently used financial ratios by financial analysts. ROA measures the ability of bank management to generate income after all financial and non- financial costs and expenses for owners. Changes in ROA are usually the cause of the most important changes in banks' performance and need a more detailed analysis (Cole, 2009). Therefore, the measure of organizational performance in this study is ROA.

\section{CONCEPTUAL FRAME WORK}

Based on the related literature of both theoretical and empirical studies the following conceptual frame work was developed.

Figure 1: conceptual frame work.

\section{Independent Variables}

\section{Dependent Variable}

\section{Transformational Leadership Style \\ - Idealized Influence \\ - Inspirational Motivation \\ - Intellectual Stimulation \\ - Individualized Consideration}

\section{Transactional Leadership Style \\ - Contingent Reward \\ - Management by Expectation -Active \\ - Management by Expectation- Passive}

Source: Self Developed Based on Literature Review

\section{RESEARCH METHODOLOGY}

\section{Research Design}

To achieve the objective of the study the causal type of research and panel design was employed. The causal research type uses to assess the nature of relationship and its extent between independent and the depended variables. On the other hand, the panel data gives the advantageous that either time series or cross sectional does not controllers individual heterogeneity, reduce co linearity variables and track trends in the data (Baltagi 2005). The research method employed in the study is quantitative, used to describe trends or tendency between variables.

\section{Target Population and sampling design}

There are 8 commercial banks that are operating in the Jimma town. The target banks are those

Operating more than five consecutive years. Hence, five commercial banks in Jimma town was fulfil the criteria. The target population became the leaders (CEOs, department level managers, and the team leaders or division managers) and their subordinate staffs of the selected commercial banks. Census were applied since the number of banks and target population within the selected banks are few in number.

\section{Data type, Sources and collection instruments}

For the purpose of the study both primary and secondary data was used. The primary data sources was collected from target population by using Multifactor Leadership Questionnaire (MLQ Form 5X) that is a validated form (instrument) that contains eight subscales and 40 items (Avolio\& Bass, 2004) will be adapted for collection of leadership styles representing questions. On the other hand, the secondary data source was the selected banks performance measurement, ROA directly from annual report of individual banks and from audit financial report of National Bank of Ethiopia (NBE). Participants were asked to rate the scale that consists 5 points, ranging from 0 to 4 , as how they "eee perceive that their leaders are the exhibiting or acting in accordance with the specific behavior explained in questions. The points are labeled as $0=$ not at all, $1=$ once in a while, $2=$ sometimes, 3 = fairly often, $4=$ frequently, if not always. 


\section{Method of Data Analysis}

Both descriptive and inferential analyses was conducted by using STATA version 14 used to facilitate the analysis. The researcher employed Random Effect Model (LM) to investigate the extent of relationship between independent variables and dependent variables.

\section{Validity test}

The multifactor Leadership Questioner will be one of the most extensively used instrument by several researchers to assess individual and organizational success and to evaluate the leadership in different fields. Avolio\& Bass (2004) pointed out as the instrument was used extensively in field and laboratory research to study transformational, transactional, and passive/avoidant leadership style. Again, they stated as the instrument has been in use for over two decades evaluating the leadership effectiveness in military, government, education, religion, and other areas. The MLQ was adopted by Walumbwa et al. (2004) and Gupta and Krishnan (2004) [ cited by Cole, 2009] ' for determination of role of collective efficacy in the relations between transformational leadership and work outcomes" and "to assist in providing an understanding of transformational leadership behaviors shown by leaders vary depending on the follower's socialization method ${ }^{\text {ee }}$ respectively.

\section{Reliability test}

The questions are requiring $10+2$ education to complete and timeframe of 15 minutes. This version of the MLQ has been updated to account for previous concerns and criticisms of the instrument (Cole 2009). Authors of this particular questionnaire have over 20 years of experience invalidating evidence for the MLQ and through that experience they have developed a strong foundation for what contributes to the success of such an instrument (Avolio \& Bass, 2004). The MLQ (5X-Short Form), which is a validated instrument that contains 40 items, was used for the research.

The value of Cronbach's Alpha (0.884) is greater than 0.5 that suggests that Categorical Data used is Reliable for Linear Regression Analysis. On the basis of Reliability test, now the Regression analysis may be made to investigate the effect of Leadership styles on the organizational Performance.

\section{Table 1. Reliability Statistics}

\begin{tabular}{|l|l|}
\hline Cronbach's Alpha & N of Items \\
\hline .884 & 9 \\
\hline
\end{tabular}

Source: Survey, 2019

\section{Results and Discussions}

This section presents the analysis, discussion and inferences made on the basis of the responses obtained. All the data were coded and entered in to STATA 14 and inferences were made based on the statistical results. The research instrument used in the study was survey questionnaire. The study population comprised the commercial banks' leaders and subordinates. Data was collected from all selected commercial bank's leaders and subordinates of 135 which comprises $85 \%$ of target population.

\section{The Descriptive Statistics}

Table 2: Leadership Styles Behavior

\begin{tabular}{|l|l|l|}
\hline Leadership Styles Behavior & Mean & Std. Deviation \\
\hline Idealized Influence (II) & 11.4074 & 1.42628 \\
Inspirational Motivation (IM) & 8.3333 & 1.66617 \\
Intellectual Stimulation (IS) & 8.5407 & 1.45460 \\
Individualized Consideration (IC) & 13.5556 & 3.44827 \\
Contingent Reward (CR) & 5.4222 & 2.91027 \\
Management- by- Exception (Active) (EMA) & 3.2222 & 3.63783 \\
Management- by- Exception (Passive)(EMP) & .2667 & 1.00149 \\
Transformational leadership behaviors (TRS) & 41.8370 & 7.54905 \\
Transactional leadership behaviors & 8.9111 & 6.27179 \\
(TSL) & & \\
Valid N (listwise) & & \\
\hline
\end{tabular}

Source: Survey,2019

The Multifactor Leadership Questionnaire table 2 provides an assessment of leadership based on seven leadership behaviors and two leadership outcomes. Through the components of transformational leadership, five leadership behaviors, assess the leader's transformational dimensions. It describes leadership behaviors that inspire, motivate, stimulate and are considerate of others' higher potential. The range of transformational leadership profile of managers were Idealized Influence - Behavior (3.25), Idealized Influence - Attributed 11.4), Inspirational 
Motivation (8.33), Intellectual Stimulation (8.54) and Individualized Consideration (13.55). They also considered their follower's opinions and communicating to followers that the vision is achievable.

Intellectual stimulation and Individualized Consideration behaviors of leaders are active one. Active transformational leadership is employed when the individual chooses leadership behavior designed to raise follower's consciousness about goals and values (Bass, 1996). Idealized influence behavior and inspirational motivation emphasize motivating followers to go beyond personal or individual interests for the good of the group (Burns, 1978). This is consistent with the findings of this study. More specifically, idealized influence is charismatic and seeks to inspire followers into action (Bass, 1996). The mean value of overall Transformational leadership behaviors of the managers is 41.83 and standard deviation is 7.5. It shows that they are also using Transformational style frequently. The leaders are monitoring and controlling outcomes at the mean time they are given the chance to follower's independent growth.

Further, transactional leadership describes Contingent Reward, Management- by- Exception (Active) and Management- by- Exception (Passive). The mean values of these dimensions are 13.5, 5.42 and 3.42 respectively. The leaders are having considerable level of Contingent Reward behavior and Passive. The leaders are classifying role of followers and they also provide material and psychological reward contingent on the fulfillment of objective. They also helped to solve the problem when compliance has occurred. The leaders are occasionally involved with the followers work to correct them. Contingent reward, although transactional, seem to suggest a leadership behavior associated with motivating others to achieve higher level of development and performance. Leader assigns or gets agreements on what need to be done, the leader set reward for the exchange of transaction like awards, medals, respect, team recognition (bas 1996). Leaders are having both transformational and transactional behaviors, with the mean values of 41.83 and 8.91 . The leaders are expected to show similar transformational and transactional leadership style. The present study result is consistent with others studies such as Bass (1985), and Avolio and Bass (1991).

\section{Relationship between Variables}

Table3 zero order correlations

- corr OP II IM IS IC CR EMA EMP

$(\mathrm{obs}=135)$

\begin{tabular}{|c|c|c|c|c|c|c|c|c|}
\hline & OP & II & IM & IS & IC & $\mathrm{CR}$ & EMA & EMP \\
\hline OP & 1.0000 & & & & & & & \\
\hline II & -0.0437 & 1.0000 & & & & & & \\
\hline IM & 0.1983 & 0.2237 & 1.0000 & & & & & \\
\hline IS & 0.6433 & 0.0600 & 0.2775 & 1.0000 & & & & \\
\hline IC & -0.1586 & 0.4025 & 0.0383 & -0.0310 & 1.0000 & & & \\
\hline $\mathrm{CR}$ & 0.1669 & 0.4009 & 0.1048 & 0.1393 & 0.6973 & 1.0000 & & \\
\hline EMA & 0.1110 & 0.4137 & 0.0402 & -0.0350 & 0.4607 & 0.5032 & 1.0000 & \\
\hline EMP & 0.3710 & 0.2477 & 0.3126 & 0.3918 & 0.0819 & 0.1683 & 0.1875 & 1.0000 \\
\hline
\end{tabular}

Table 4: Partial and semipartial correlations of Performance with

Partial and semipartial correlations of OP with

\begin{tabular}{|c|c|c|c|c|c|}
\hline & Partial & Semipartial & Partial & Semipartial & Significance \\
\hline Variable & Corr. & Corr. & $\operatorname{Corr.\wedge } 2$ & $\operatorname{Corr} \cdot{ }^{\wedge} 2$ & \\
\hline II & -0.2101 & -0.1409 & 0.0442 & 0.0198 & 0.016 \\
\hline IM & 0.0334 & 0.0219 & 0.0011 & 0.0005 & 0.706 \\
\hline IS & 0.5878 & 0.4762 & 0.3455 & 0.2268 & 0.000 \\
\hline IC & -0.3757 & -0.2657 & 0.1412 & 0.0706 & 0.000 \\
\hline $\mathrm{CR}$ & 0.2836 & 0.1938 & 0.0805 & 0.0376 & 0.0011 \\
\hline EMA & 0.2318 & 0.1562 & 0.0537 & 0.0244 & 0.0082 \\
\hline EMP & 0.2800 & 0.1912 & 0.0784 & 0.0365 & 0.001 \\
\hline
\end{tabular}

As the above partial correlation coefficient table reveals that there is moderate positive relationship between performance and Intellectual stimulation, Contingent rewards, Management- by- Exception (Active) and 
Management- by- Exception (Passive) with $\mathbf{r}$ value $\mathbf{0 . 5 9}, \mathbf{0 . 2 8 , 0 . 2 3}$ and $\mathbf{0 . 2 8}$ respectively. Whereas, weak positive relationship with Inspirational motivation with $\mathbf{r}$ value $\mathbf{0 . 0 3}$. While, there is moderate negative relationship between performance and Idealized influence and Individualized consideration with $\mathbf{r}$ value $\mathbf{0 . 2 1}$ and $\mathbf{0 . 3 8}$ respectively. When we compare zero order correlation with partial correlation high change occurred on variable Inspirational motivation that reduced almost by greater than $\mathbf{1 6 \%}$ (from $\mathbf{0 . 1 9 8 3}$ to $\mathbf{0 . 0 3 3 4}$ ). Hence, Inspirational motivation variable should be removed from the model from further analysis.

\section{Regression Assumptions}

It is better to check for sum assumption of CLRM before, dealing with the results of the regression analysis.

\section{Checking Normality of Residuals}

Fig 2: normality of the residual

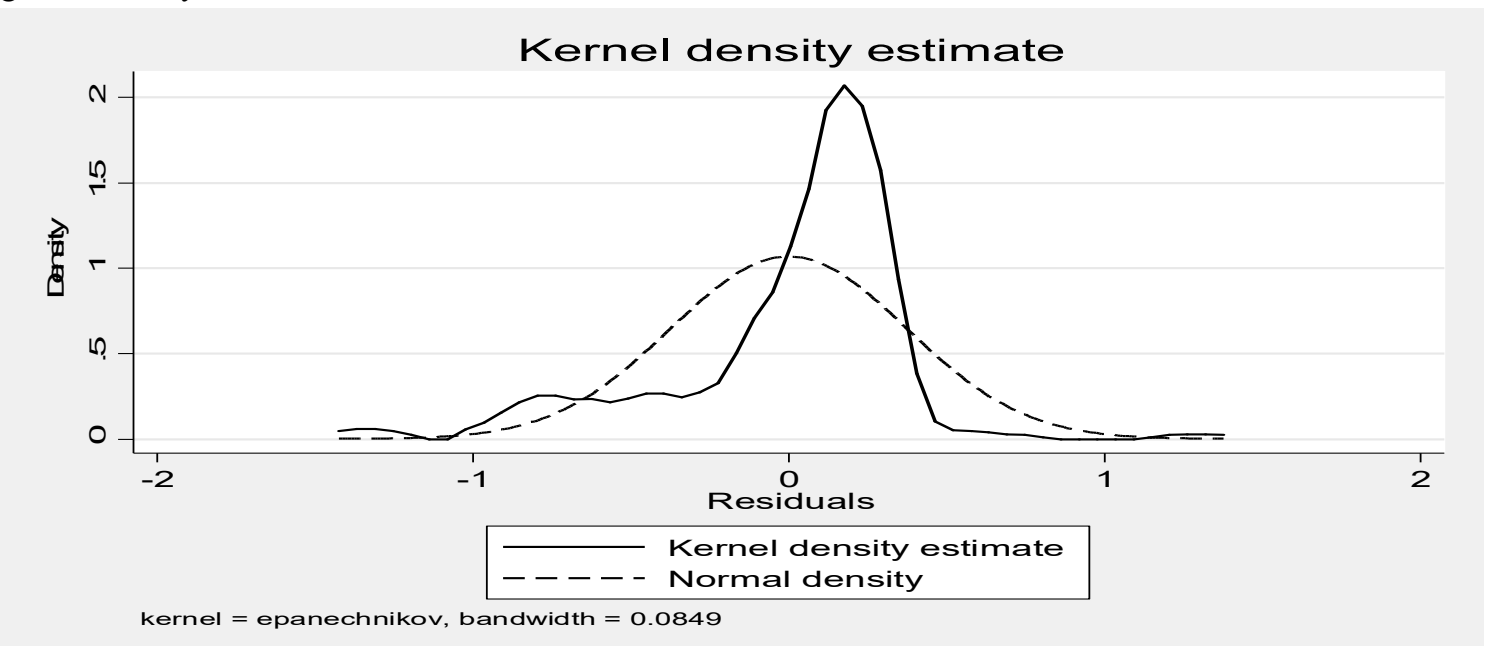

As the estimates of kernel density figure above show the sign of normal distribution. Therefore, the residual has not the issue normality.

\section{Checking Homoscedasticity of Residuals}

Table5 homoscedasticity of residuals

. estat hettest

\section{Breusch-Pagan / Cook-Weisberg test for heteroskedasticity}

\section{Ho: Constant variance \\ Variables: fitted values of lwage}

$\begin{array}{ll}\operatorname{chi2}(1) & =0.00 \\ \text { Prob }>\text { chi2 } & =0.9759\end{array}$

estat imtest

Cameron \& Trivedi's decomposition of IM-test

\begin{tabular}{r|rrc}
\hline Source & chi2 & df & p \\
\hline Heteroskedasticity & 38.64 & 33 & 0.2300 \\
Skewness & 13.27 & 7 & 0.0658 \\
Rurtosis & 0.75 & 1 & 0.3860 \\
\hline Total & 52.66 & 41 & 0.1048 \\
\hline
\end{tabular}

From the above Table of homoscedasticity of residuals after normalization as estat imtest of the null 
hypothesis that the variance of the residuals homogenous have the respective P-values are larger, we would not reject the null hypothesis of variances of residuals is homogeneous.

Checking for Model Specification

\section{Table6 model specification 1}

- linktest

\begin{tabular}{|c|c|c|c|c|c|c|}
\hline Source & S S & $d f$ & MS & \multirow{2}{*}{$\begin{array}{l}\text { Number of obs } \\
\mathrm{F}(2,132)\end{array}$} & $=$ & \multirow{2}{*}{$\begin{array}{r}135 \\
88.78\end{array}$} \\
\hline & & & & & $=$ & \\
\hline Model & 24.9410176 & 2 & 12.4705088 & Prob $>F$ & $=$ & 0.000 \\
\hline Residual & 18.5404639 & 132 & .14045806 & R-squared & $=$ & 0.573 \\
\hline & & & & Adj R-squared & $=$ & $0.56^{\circ}$ \\
\hline Total & 43.4814815 & 134 & .324488668 & Root MSE & $=$ & .3747 \\
\hline
\end{tabular}

\begin{tabular}{|c|c|c|c|c|c|c|}
\hline OP & Coef. & std. Err. & t & $P>|t|$ & [ $95 \%$ Conf. & Interval] \\
\hline hat & 2.056249 & 1.00788 & 2.04 & 0.043 & .0625629 & 4.049935 \\
\hline _hatsq & -.1517419 & .1443887 & -1.05 & 0.295 & -.4373571 & .1338732 \\
\hline & -1.806853 & 1.74117 & -1.04 & 0.301 & -5.25106 & 1.637354 \\
\hline
\end{tabular}

From the above linktest, the test_hatsq is not significant. This is to say that linktest has failed to reject the assumption that the model is specified correctly. Therefore, it seems that there is no a specification error. But now, let's look at another test before we go to the conclusion which ovtest which is very similar to linktest.

\section{Table 6 model specification 2}

- ovtest

\section{Ramsey RESET test using powers of the fitted values of lwage \\ Ho: model has no omitted variables}

$$
\begin{array}{ll}
\mathrm{E}(3,89)= & 1.55 \\
\text { Prob }>\mathrm{F}= & 0.2064
\end{array}
$$

The ovtest command indicates that there are no omitted variables. As it shown in the above table of model specification 1 and 2 both the linktest and ovtest do not have the problem of model specification i.e. the linktest is non-significant while the P-value for ovtest is fine greater than $\mathbf{5 \%}$ significant level, therefore it possible to do further analysis.

\section{Checking for Multicollinearity}

Table 7: Multicollinearity

- vif

\begin{tabular}{r|cr} 
VariabIe & VIF & I/VIF \\
\hline CR & 2.27 & 0.439663 \\
IC & 2.12 & 0.471949 \\
EMA & 1.50 & 0.664511 \\
II & 1.34 & 0.745185 \\
EMP & 1.19 & 0.838276 \\
IS & 1.19 & 0.842785 \\
\hline Mean VIF & 1.60 &
\end{tabular}

As it shown table above the 1/VIF of all independent variables are greater than 0.1 and the VIF value of all the independent variables are also less than 10 . Therefore, there is no multicollinearity problem among each independent variable. 
Regression Analysis

Table 8: Regression summary

- reg OP II IS IC CR EMA EMP

\begin{tabular}{r|crc} 
Source & SS & df & MS \\
\hline $\begin{array}{r}\text { Model } \\
\text { Residual }\end{array}$ & $\begin{array}{r}24.7858895 \\
18.6955919\end{array}$ & 128 & .146059312 \\
\hline Total & 43.4814815 & 134 & .324488668
\end{tabular}

Number of obs
F(6, 128)
Prob $>\mathrm{F}$
R-squared
Adj R-squared
Root MSE

\begin{tabular}{|c|c|c|c|c|c|c|}
\hline OP & Coef. & std. Err. & t & $P>|t|$ & [95\% Conf. & Interval] \\
\hline I I & -.0880982 & .0366549 & -2.40 & 0.018 & -.1606263 & -.0155701 \\
\hline IS & .5332543 & .0626542 & 8.51 & 0.000 & .4092824 & .6572263 \\
\hline I C & -.3843581 & .083558 & -4.60 & 0.000 & -.5496919 & -.2190243 \\
\hline $\mathrm{CR}$ & .4349765 & .1297491 & 3.35 & 0.001 & .1782458 & .6917072 \\
\hline EMA & .1254205 & .0467893 & 2.68 & 0.008 & .0328399 & .2180012 \\
\hline EMP & .1587094 & .047544 & 3.34 & 0.001 & .0646354 & .2527834 \\
\hline _cons & .6432268 & .4027445 & 1.60 & 0.113 & -.153672 & 1.440126 \\
\hline
\end{tabular}

From the regression summary the $\mathrm{R}$ squared is $\mathbf{0 . 5 7}$ which shows that the six independent variables included in the model are able to explain $57 \%$ of the variation in the dependent variable, Banks performance. Adjusted Rsquared (adj. $\mathrm{R}^{2}$ ) is $\mathbf{0 . 5 4 9 9}$. It means that 55 percent of the total variability of the dependent variable (Banks performance) is explained by the stated six independent variables and 45 percent of it is explained by other variables. The estimated models show that the coefficients are consistent with expectations, except Idealized influence (II) and Individualized consideration (IC) which accounts negative effect on banks performance. Further, the regression coefficient indicates as the dimension of transformational leadership style accounts higher effect on banks performance than the transactional leadership style dimensions. That is, in the surveyed banks, performance is positively correlated with transactional leadership style than transformational leadership style. Consequently, it can be concluded that in that in the banks, while transactional leadership style has significant positive effect on performance, the effect of transformational leadership style on performance is insignificant.

A possible reason for this is that the employees of banks are usually the reward in exchange for the extra effort, recognition of the work are common in Ethiopian banking sector: bonus, promotion, salary increment takes place when banks get profit that employee are committed and perform well to be rewarded. Therefore, contingent recognition/reward and management by exception rather than charisma, inspirational motivation and intellectual stimulation/individual consideration could be appropriate leadership behaviors and strategies to induce them to perform.

\section{Conclusion}

According to the respondents ${ }^{\text {ee }}$ perceptions, idealized influence is relatively most exhibited component of transformational leadership style followed by intellectual stimulation and individual consideration, while inspirational motivation is the least exhibited component of transformational leadership style with the mean score of only 8.91 .

On the other hand, management by exception - active has been perceived as relatively more exhibited component of transactional leadership style as compared with contingent reward and management by exceptionpassive.

The random effect regression was carried out to examine how and to what extent each type of leadership style relates to banks performance, which, is measured in terms, ROA. The result for two of leadership styles: transformational and transactional revealed the existence of positive relationship with ROA. Both transformational and transactional leadership styles are found to have strong positive effect on the ROA.

Strong and positive relation for transformational leadership shows that the leadership style that involves changes and transformation of an organization as well as of individual performer fits for today business that is operating in dynamic environment. Transformational leaders instill confidence, build trusts, encourage creativity and innovation, motivate and inspire workers to achieve organizational goal; and make employee to perform what they thought is impossible. This kind of leadership style makes employee to handle and overcome the problems and challenges that is arising from current dynamic environment of individual bank and there by maintain the profitability of bank. 
On the other hand, the existence of positive and strong relation of transactional leadership style on the ROA implies the reward and recognitions that leaders make for fellow subordinates up on accomplishment of the given task has strong effect on the performance. The reward or compensation for the work performed; in bank cases bonus, salary increment can increase the performance of an individual there by the banks. Again, employees need to know what their mangers/leaders them to do, in which standards and thereby want to get close assistance especially when they are new for the task.

This study has found out that the behaviors that associated with transformational and transactional leadership have more effect on organizational performance. In the context of Ethiopian banking sector, transformational leadership which focuses on change and transformation of organization and individual performer and, the transactional leadership which involves reward and recognition in exchange for the work done and close assistant and guidance are more relevant.

\section{Recommendation}

Based on the resulted findings of the study, the researcher forwarded the following:

\section{Recommendations for Bank Leaders}

The bank leaders in Ethiopia are recommended to exhibit the combination of both transformational and transactional leadership behaviors according to the ongoing work environment circumstances. The leaders of banks should focus on playing a role model by taking first step of what they talk about and keep consistent in their action in way that getting trust and loyalty from employees and in instilling confidence, commitment and vision in employees. In this way leaders can get employee's work commitment or improvement in their performance by assuring the psychological attachment of employees to the organization. They should encourage participation in decision making, leave much room for the employees say and delegate and make to feel full responsible.

In order to cope up with ongoing and upcoming changes in the banking environment, the leaders in banks should a quire predictable ability and prepare in advance by giving more focus for research and development, making the working environment suit for creativity and innovation, and appreciating and entertaining of different ideas arises from individual or group of employees.

On the other hand the leaders in the bank should give attention to close guidance and close follow up or supervision to the employees when the employee seem new for the work at the hand. The leader should also tell clearly what is expected from the employee and attached rewards and recognition for the achievement to induce the improvement of the performance of employee and then bank as a whole.

\section{Recommendations for Banks Stakeholders}

Stakeholders in the industry should consider taking banking in a non-traditional direction by placing more emphasis on understanding leadership style and its effects on improving results. The leadership style is learnable that the stakeholders of the bank should consider the need to present training to leaders on leadership styles as a means to increase performance results. The stake holders might also consider holding national conferences on innovative leadership models used to support the vision of the banking industry and seminars might be warranted to show financial leaders how to apply leadership models to everyday activities and develop strategies that might goes with contemporary banking environment.

\section{REFERANCE}

Ghirmai T Kefela (2008). Regulatory Challenges Strategically Enhance Banking Efficiency and stability: The study of East African countries .Indus Journal of Management \& Social Sciences Vol.2, No. 2:-129-147

HabtamuNegussieAyele(2012). Determinants of Bank Profitability: An Empirical Study on Ethiopian Private Commercial Banks. Master"es Thesis .Addis Ababa University Addis Ababa

Hair, J F, Black, W C, Babin, B J, Anderson, R E, and Tatham, R L (6thedn). (2006). Multivariate Data Analysis. New Jersey: Pearson Education.

Hun MyoungPark(2011). Practical Guides To Panel Data Modeling: A Step by Step Analysis Using Stata. Public Management and Policy Analysis Program. Graduate School of International Relations International University of Japan777 Kokusai-cho Minami Uonuma-shi, Niigata 949-7277, Japan(025) 779-1424

http://www.iuj.ac.jp/faculty/kucc625

James, K. \& Collins, J. (2008).Leadership Perspectives: Knowledge into Action. London:

Judge, T. A. \& Piccolo, R. F. (2004). Transformational \& Transactional Leadership: A Meta-analytic Test of their Relative Validity. Journal of Applied Psychology, 89(5): 755-768.

Kozo Kiyota, Barbara Peitsch, and Robert M Stern (2007). The Case for Financial Sector Liberalization in Ethiopia ILO (2009).Private Sector"s Responses to the Current Global Financial and Economic Crisis: The Case of Ethiopia. Addis Ababa

Imad Z. Ramadan, Qais A. Kilani, Thair A. Kaddumi (2011). Determinants of Bank Profitability: Evidence from Jordan. International Journal of Academic Research Vol. 3.No. 4. 